\title{
Lepeophtheirus simplex sp. n., a caligid copepod (Siphonostomatoida) parasitic on "botete" (bullseye puffer, Sphoeroides annulatus) in Sinaloa, Mexico
}

\author{
Ju-shey Ho ${ }^{1}$, Samuel Gómez ${ }^{2}$ and Emma Fajer-Avila ${ }^{3}$ \\ ${ }^{1}$ Department of Biological Sciences, California State University, Long Beach, California 90840-3702, USA; \\ ${ }^{2}$ Instituto de Ciencias del Mar y Limnologia, Unidad Académica Mazatlán, Joel Montes Camarena s/n, Ap. Postal 811, C.P. \\ 82040, Mazatlán, Sinaloa, México; \\ ${ }^{3}$ Unidad Mazatlán en Acuicultura y Manejo Ambiental, CIAD, A.C., Ap. Postal 711, C.P. 82010, Mazatlán, Sinaloa, México
}

Key words: Lepeophtheirus simplex, fish parasite, parasitic copepod, Caligidae, Mexico

\begin{abstract}
A new species of caligid copepod, Lepeophtheirus simplex sp. n., parasitic on bullseye puffer, Sphoeroides annulatus (Jenyns) in Sinaloa, Mexico is described. The new species is distinguished from its congeners by the possession of (1) a maxillule with simple dentiform process; (2) a sternal furca with sharply pointed, curved tines; (3) a 2-segmented exopod of leg 3 with simple, slender spine on proximal segment; (4) a 3-segmented exopod of leg 4 with a long proximal, outer spine; and (5) the terminal claw of male antenna with a large, tridentate, medial protuberance.
\end{abstract}

Due to its potential for aquaculture, the biology of "botete" [bullseye puffer, Sphoeroides annulatus (Jenyns)] in the state of Sinaloa, Mexico was closely studied at Unidad Mazatlán en Acuicultura y Manejo Ambiental. The parasite fauna of the wild bullseye puffers was investigated and a new species of Lepeophtheirus Nordmann, 1832 (Caligidae, Siphonostomatoida) was found.

Only two species of Lepeophtheirus have so far been reported from fishes of the Pacific coast of Mexico (Causey 1960). They are $L$. dissimulatus Wilson and $L$. thompsoni Baird. However, the record of $L$. thompsoni from the "white seabass (corvine), Cynoscion nobilis" caught at "Cholla Bay near Puerto Penasco, Sonora; Guaymas, Sonora; San Blas, Nayarit; and Acapulco Guerrero" provided by Causey (1960, p. 330) is questionable, because this parasite is essentially a European species. Nevertheless, by the possession of a 2segmented (instead of 3-segmented) exopod on leg 3 and armed with a straight, slender spine (instead of stout, claw-like spine) on the proximal segment, those specimens obtained from the bullseye puffer are not identifiable with either of these two species. Comparison with other congeners showed them to be a new species.

\section{MATERIALS AND METHODS}

Altogether 77 bullseye puffers from three different locations (Mazatlán, Teacapán, and Chametla) in Sinaloa State were examined from August 1998 to June 1999. The fish ranged between 22 and $28 \mathrm{~cm}$ in standard length and weighed from 120 to $900 \mathrm{~g}$. Copepods removed from the fish were preserved in $70 \%$ ethanol. Specimens were dissected in a drop of glycerin and the body parts and appendages mounted as semi-permanent slides using glycerin as mounting medium and examined microscopically. All drawings were made with the aid of a camera lucida. A full description is given of the female and only those parts and appendages showing sexual dimorphism are described of the male. Measurements (in millimetres unless stated otherwise) given for various parts of the body are those of the holotype female and allotype male.

\section{RESULTS}

Lepeophtheirus simplex sp. n.

Figs. 1-6

Female. Body (Fig. 1A) length $3.43 \pm 0.04$ (3.12$3.78 ; \mathrm{n}=15$ ), excluding setae on caudal rami. Cephalothoracic shield nearly as long 1.79 as wide 1.80 , excluding marginal hyaline membranes. Fourth pediger slightly wider $(369 \mu \mathrm{m})$ than long $(326 \mu \mathrm{m})$. Genital complex (Fig. 1B) longer than wide $1.56 \times 1.23$ and sparsely covered with spinules; anterocentral portion protruded into a form of stem connecting to fourth pediger, posteroventral portion between fifth legs with or without shield-like plate holding spermatophores (Figs. 1D, E). Abdomen (Fig. 1B) not clearly separated from genital complex, trapezoidal, and about as long $(278 \mu \mathrm{m})$ as wide $(289 \mu \mathrm{m})$. Caudal ramus (Fig. 1C) small, $53 \mu \mathrm{m}$ long and $56 \mu \mathrm{m}$ wide, carrying 3 short and 3 long plumose setae. Egg sac about one-half of body length, containing about 20 eggs.

Frontal plate (Fig. 1A) with 1 setule on anterior margin near centre. Antennule (Fig. 2A) 2-segmented; proximal segment with 27 plumose setae on frontal surface, distal segment with medial seta on posterior 

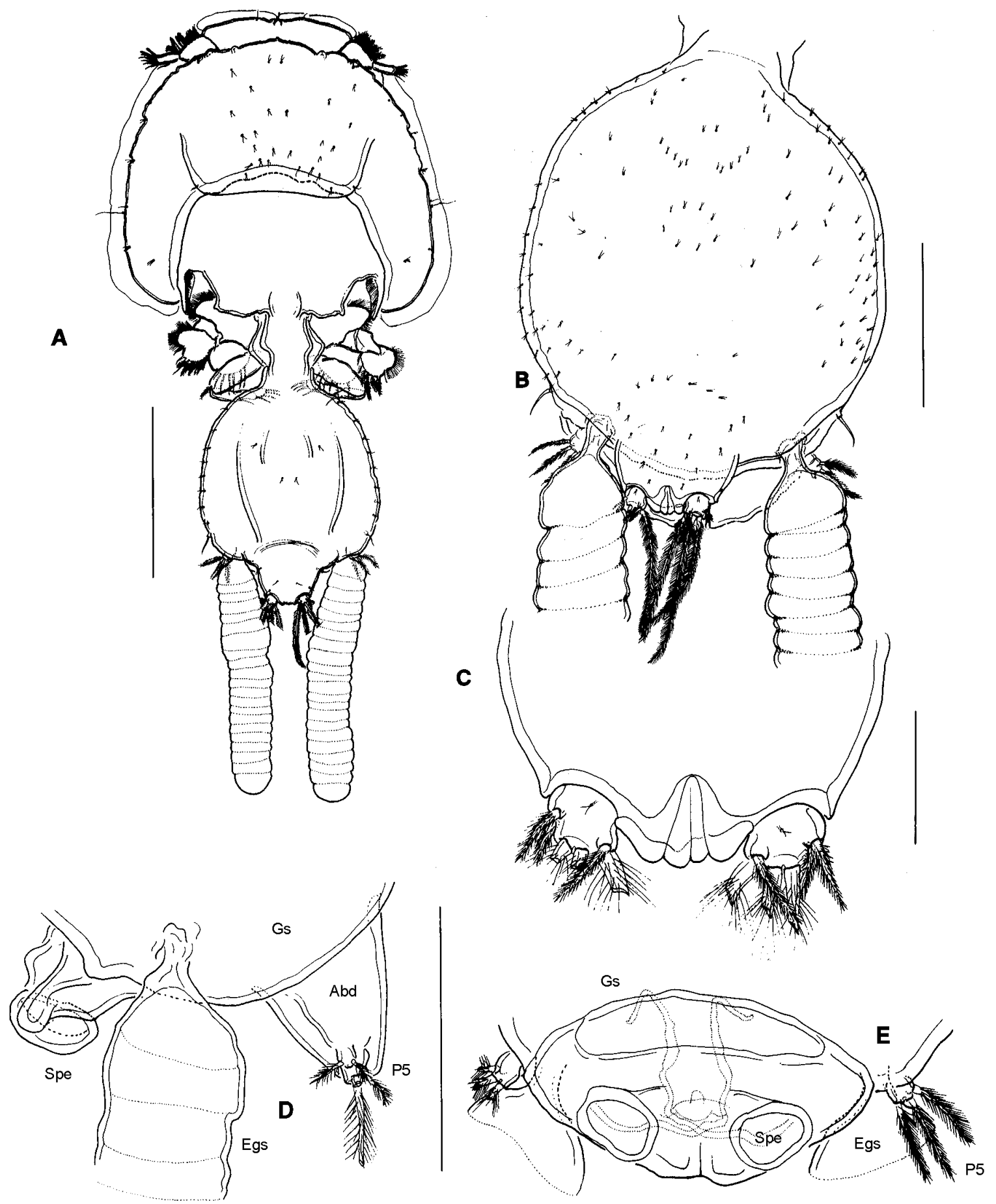

Fig. 1. Lepeophtheirus simplex sp. n. Female. A - habitus, dorsal view; B - posterior half of body, dorsal view; $\mathbf{C}$ - abdomen and caudal rami, dorsal view; D - posterior end of genital complex, lateral view; $\mathbf{E}$ - posterior end of genital complex, ventral view. Abbreviations: Abd - abdomen; Egs - egg sac; Gs - genital complex; P5 - leg 5; Spe - spermatophore. Scale bars: A = $1 \mathrm{~mm}$; $\mathrm{B}, \mathrm{D}, \mathrm{E}=0.5 \mathrm{~mm} ; \mathrm{C}=0.1 \mathrm{~mm}$. 


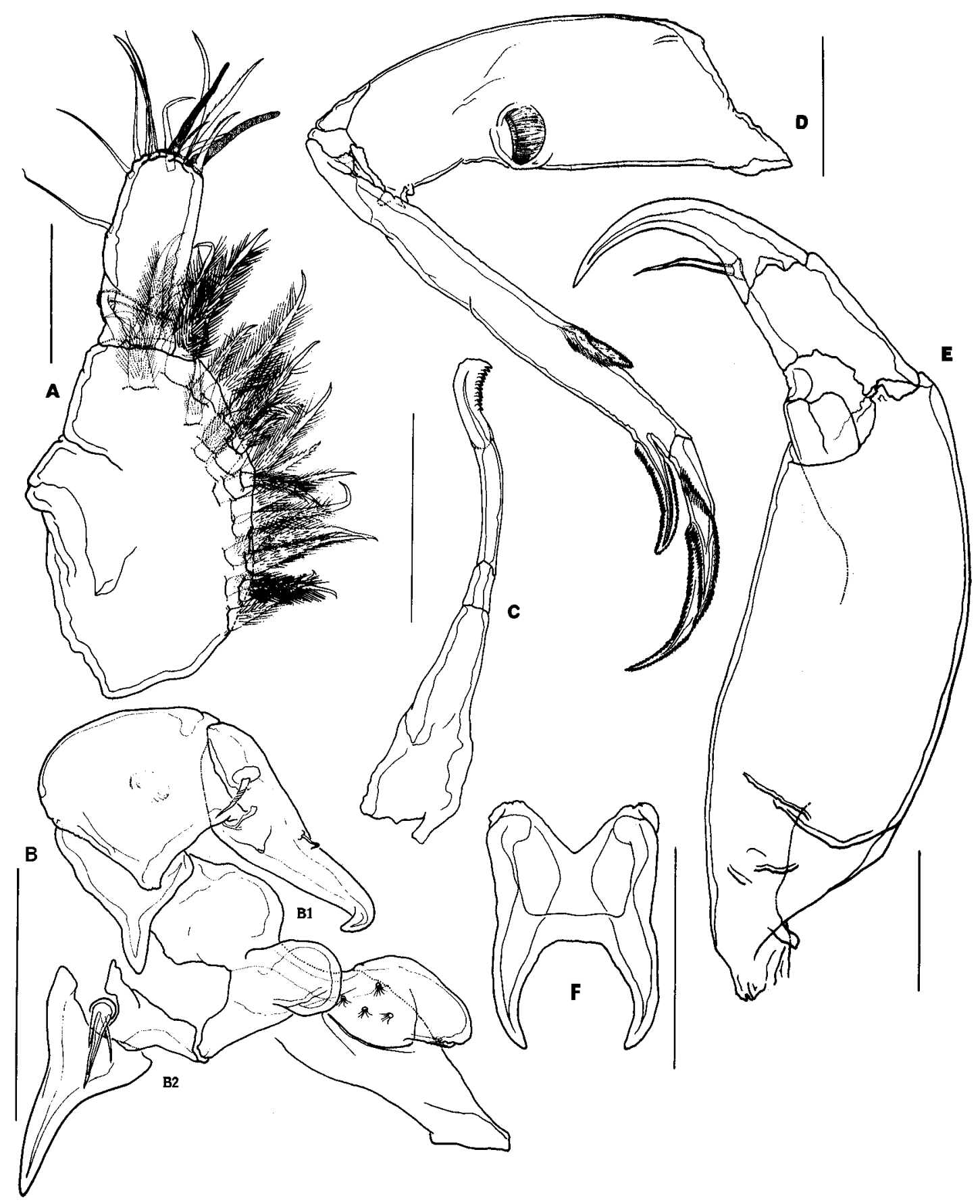

Fig. 2. Lepeophtheirus simplex sp. n. Female. A - antennule, dorsal view; B - antenna, postantennal process (B1) and maxillule (B2), ventral view; $\mathbf{C}$ - mandible; D - maxilla, anterior view; $\mathbf{E}$ - maxilliped, posterior view; $\mathbf{F}$ - sternal furca. Scale bars: 0.1 $\mathrm{mm}$ in all drawings.

margin and 11 setae plus 2 aesthetascs on distal margin. Antenna (B1 in Fig. 2B) 3-segmented; proximal segment smallest, with sharply pointed postero-medial process; second segment rectangular and with small corrugated pad on posterior surface; distal segment sharply pointed and strongly bent claw bearing 1 seta in proximal region and another one in middle region. Postantennal process (Fig. 2B) comprising massive base with 4 papillae bearing setules and broadly rounded shaft. A large spherical outgrowth located between bases of antenna and postantennal process (Fig. 2B). Mandible (Fig. 2C) with 3 annulations and bearing 12 teeth on medial margin of distal blade. Maxillule (B2 in Fig. 2B) comprising long, slender, pointed process and papilla with 3 unequal setae. Maxilla (Fig. 2D) 2segmented; proximal segment (lacertus) large, with 


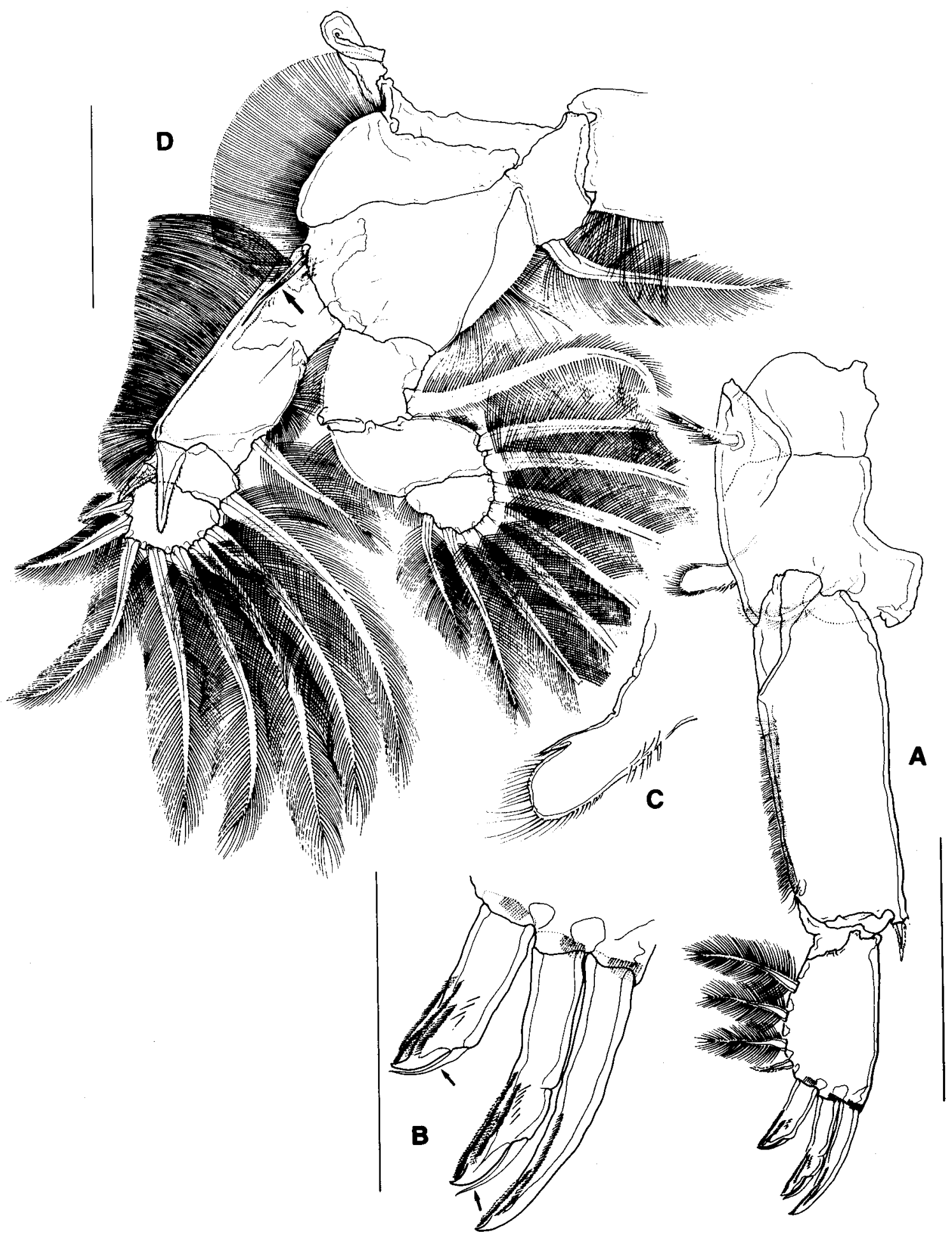

Fig. 3. Lepeophtheirus simplex sp. n. Female. A - leg 1, anterior view; B - tip of leg 1 exopod, anterior view; $\mathbf{C}-$ vestigial endopod, anterior view; D - leg 2, anterior (ventral) view. Arrows indicate accessory process on terminal spines of leg 1 and outer basal seta on leg 2. Scale bars: $A=0.2 \mathrm{~mm} ; \mathrm{B}, \mathrm{D}=0.1 \mathrm{~mm}$. (Scale for $\mathrm{C}$ as in $\mathrm{B}$.) 


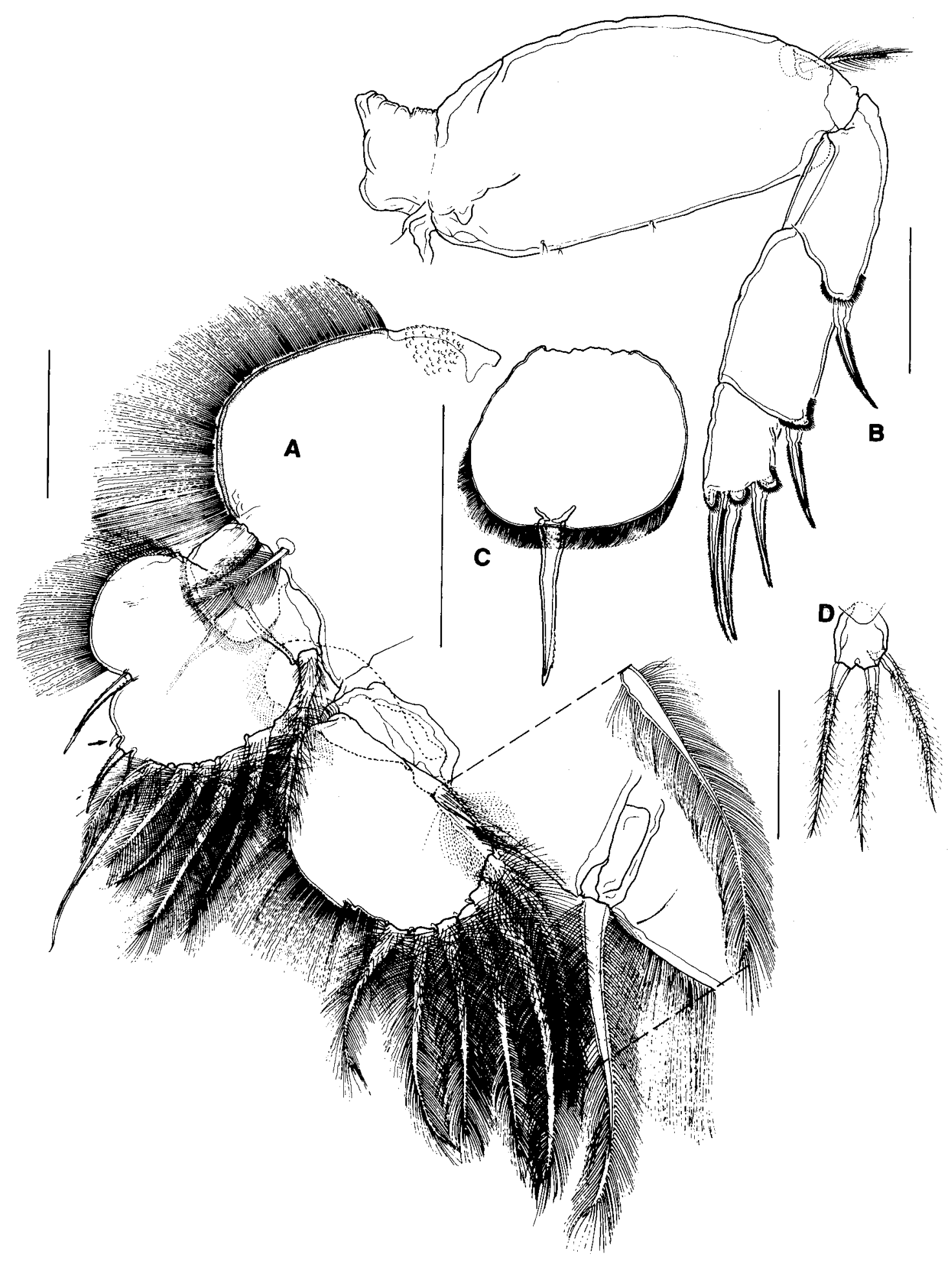

Fig. 4. Lepeophtheirus simplex sp. n. Female. A - leg 3, dorsal view; $\mathbf{B}-\operatorname{leg} 4$, anterior view; $\mathbf{C}$ - proximal segment of leg 3 exopod, ventral view; D - part of leg 5. Arrow indicates a small spiniform outer element on second segment of leg 3 exopod. Scale bars: $0.1 \mathrm{~mm}$ in all drawings. 

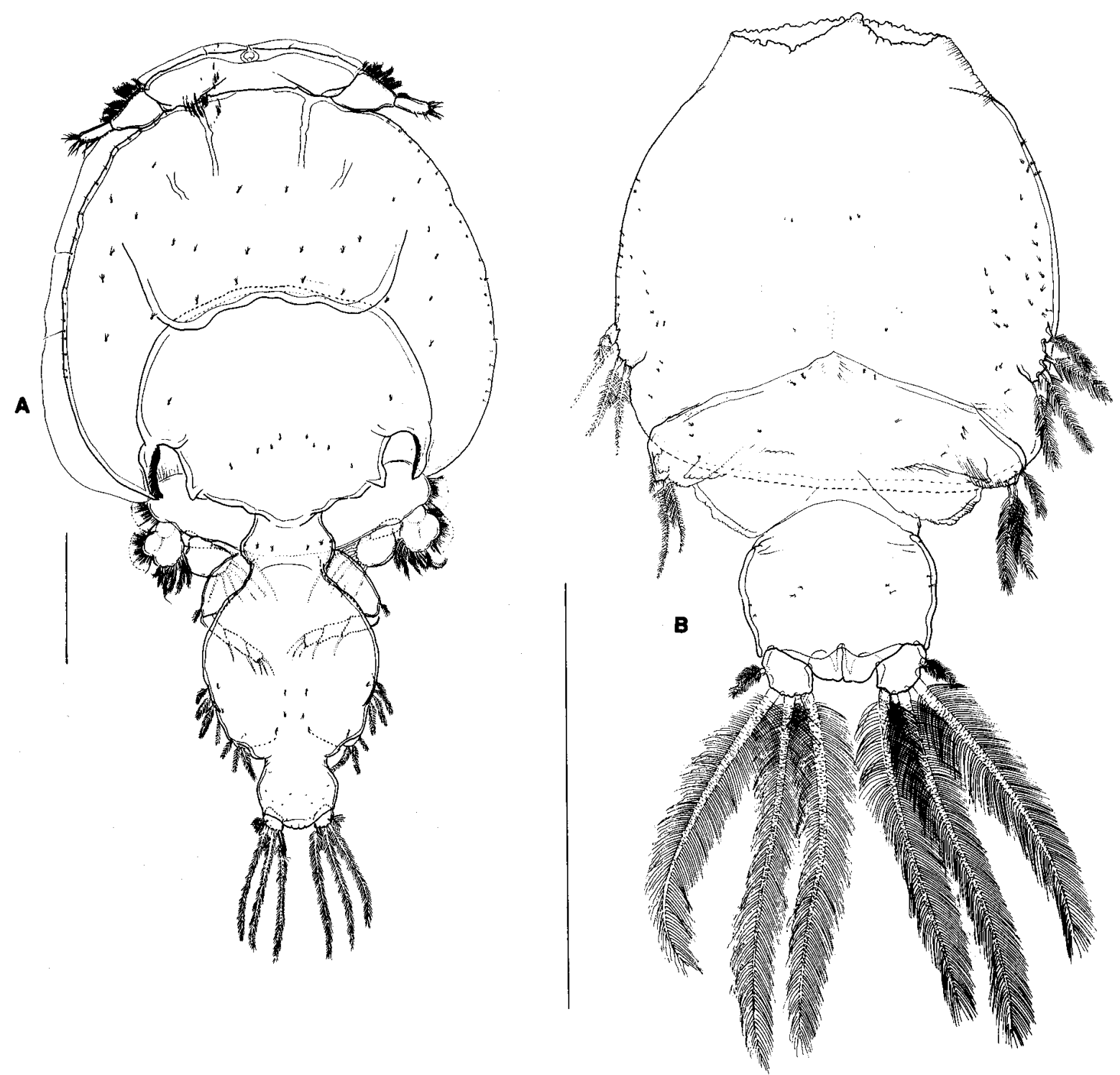

Fig. 5. Lepeophtheirus simplex sp. n. Male. A - habitus, dorsal view; B - posterior half of body, ventral view. Scale bars: $0.5 \mathrm{~mm}$ in both drawings.

anteromedial hyaline membrane; slender, distal segment (brachium) carrying small subterminal hyaline membrane on outer edge and 2 unequal elements (calamus and canna) terminally. Maxilliped (Fig. 2E) 3segmented; proximal segment (corpus) largest but unarmed; middle and distal segments fused (but leaving a distinct suture) to form strong, sharply pointed claw carrying medial seta. Sternal furca (Fig. 2F) with pointed, inwardly curved tines.

Armature on rami of legs 1-4 as follows (Roman numeral indicating spines and Arabic numeral, setae):

\begin{tabular}{lll} 
Leg 1 & \multicolumn{1}{c}{$\begin{array}{c}\text { Exopod } \\
\text { I-0; III,I,3 }\end{array}$} & \multicolumn{1}{c}{ Endopod } \\
(vestigial)
\end{tabular}

Leg 1 (Fig. 3A) protopod with plumose outer seta and another plumose inner seta; endopod (Fig. 3C) with median barb in addition to being rimmed with hairs; first segment of exopod with row of setules along posterior edge and short spiniform seta at outer distal 

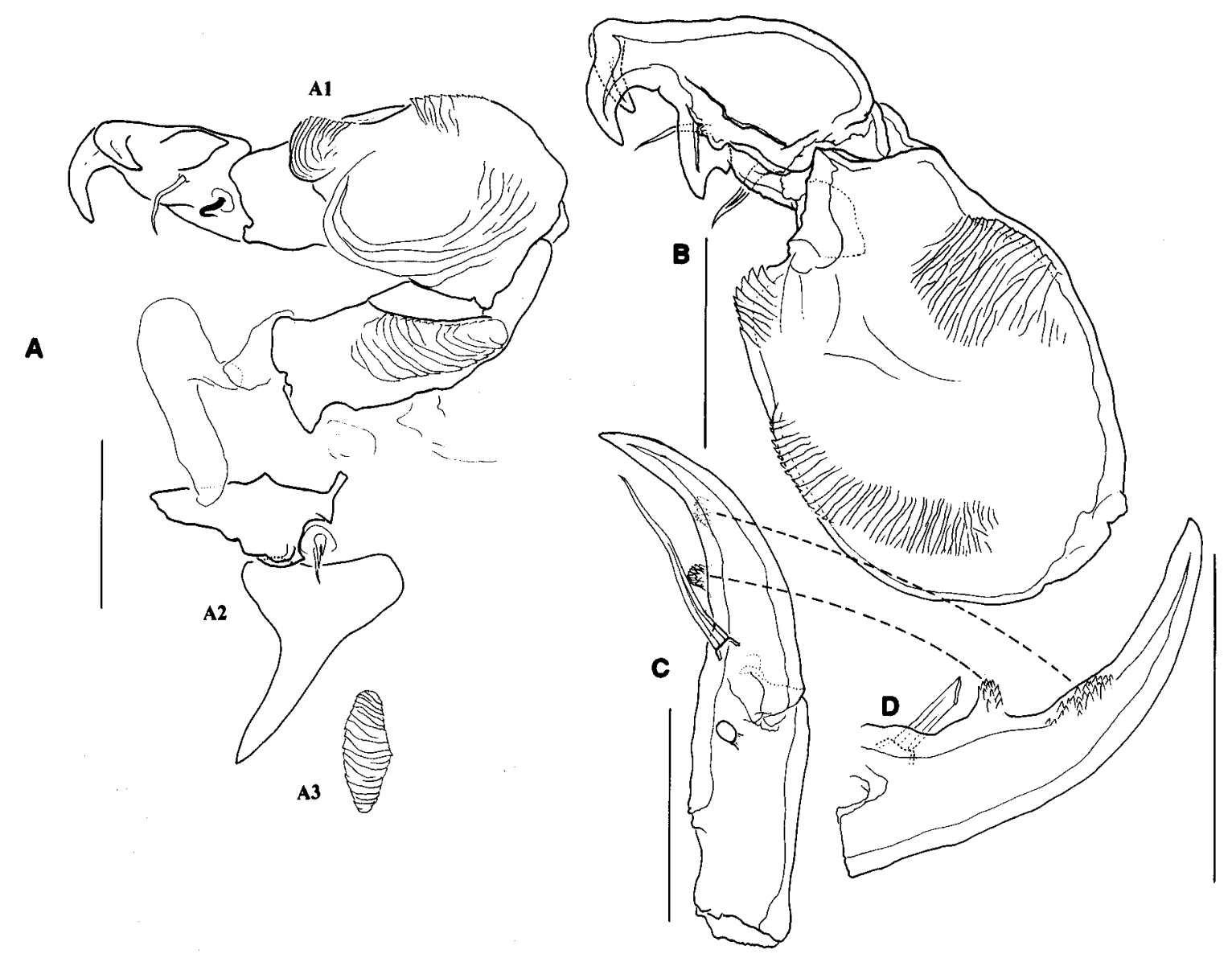

Fig. 6. Lepeophtheirus simplex sp. n. Male. A - antenna (A1), maxillule (A2) and corrugated pad (A3), anterior view; B - middle and terminal segments of antenna, posterior view; C - claw of maxilliped, anterior view; D - same, posterior view. Scale bars: $0.1 \mathrm{~mm}$ in all drawings.

corner; middle 2 of 4 terminal elements on last segment of exopod with accessory process (indicated with arrows in Fig. 3B), 3 medial plumose setae short. Leg 2 (Fig. 3D) coxa small, with large plumose inner seta on posterior edge; basis with small, naked outer seta (arrowed in Fig. 3D); both outer and medial edge of protopod fringed with large marginal membrane. Leg 3 (Fig. 4A) protopod (apron) with patch of fine denticles on dorsal surface of outer proximal corner followed by a large marginal membrane, posterior edge with small, plumose seta in distal outer corner and large, plumose seta in inner distal corner. Both rami 2-segmented; exopodal spine on proximal segment slender (Fig. 4C). Leg 4 (Fig. 4B) protopod with long, plumose outer seta; pectens on exopod segments at insertion of each outer spine. Leg 5 represented by simple seta and small process tipped with 3 plumose setae (Figs. 1E, 4D).

Male. Body (Fig. 5A) length $2.54 \pm 0.09$ (2.03-2.92; $\mathrm{n}=5$ ), excluding setae on caudal rami. Cephalothoracic shield longer than wide, $1.84 \times 1.78$, excluding marginal hyaline membranes. Genital complex (Fig. 5B) longer than wide, $916 \times 786 \mu \mathrm{m}$, and sparsely covered with setules. Abdomen (Fig. 5B) short and slightly wider than long, $364 \times 389 \mu \mathrm{m}$. Antenna (A1 in Fig. 6A) 3segmented; proximal segment with corrugated pad; middle segment largest, armed with 3 corrugated pads (Fig. 6B); terminal segment prehensile, bifurcate distally and armed with 2 spiniform setae and large, tridentate, medial protuberance (Fig. 6B). Corrugated pad (A3 in Fig. 6A) posterior to maxillule (A2 in Fig. $6 \mathrm{~A}$ ). Terminal claw of maxilliped armed with patch of denticles and denticulate median protuberance in addition to long spiniform seta (Figs. 6C, D). Leg 5 (Fig. 5B) represented by plumose seta and papilla tipped with 3 plumose setae. Leg 6 (Fig. 5B) represented by plumose seta and papilla tipped with 2 plumose setae.

$\mathrm{T}$ y p e h o s t : Sphoeroides annulatus (Jenyns, 1842) (Tetraodontidae, Tetraodontiformes).

$\mathrm{S}$ i t e of i n f e c t i o $\mathrm{n}$ : General body surface including gill cavities.

T y p e 1 o c a 1 i t y: Teacapán, Sinaloa State, Mexico. 
Prevalence and intens ity:63\% (15 fish infected/ 24 fish collected in August 1998); mean intensity 2.6 copepods.

E t y $\mathrm{m}$ o 1 o g y : The species name simplex, from Latin meaning unmixed or single, refers to the single tine on the maxillule and the simple, slender, proximal spine on leg 3 exopod.

D e p o s ition of t y p e s: Holotype $q$ (USNM 269413), allotype $\delta$ (USNM 269414) and 27 paratypes (USNM 269415; 25 우우, 2 ठ하) deposited in the National Museum of Natural History, Smithsonian Institution, Washington, D.C., USA. Additional material (30 우우 and $4 \hat{\delta} \delta^{\text {) }}$ has been deposited in the copepod collection of the Instituto de Ciencias del Mar y Limnologia, Unidad Académica Mazatlán (Nos. EMUCOP 010999-1 to 010999-10). Other intact specimens deposited at Unidad Mazatlán en Acuicultura y Manejo Ambiental, CIAD, A.C., Mazatlán, Mexico.

\section{DISCUSSION}

The most distinctive characteristic of the new species is the possession of a slender, straight, spiniform process (instead of a short, robust claw) on the proximal segment of the exopod of leg 3 (see Figs. 4A, C). This unusual feature is shared with only one other species of Lepeophtheirus Nordmann, 1832, L. orbicularis Shiino, 1965 , where it is a slender setiform process.

So far 133 species of caligid copepods have been placed in the genus Lepeophtheirus Nordmann, 1832, but according to Ho and Lin (2000), only 107 of them are currently classified in this genus. Examination of the literature on these 107 species revealed that in 17 of them the armature on the exopod of leg 3 is unknown; it was neither described nor illustrated in the original or any subsequent supplemental descriptions. These 17 species are (in alphabetical order): L. appendiculatus Krøyer, 1863; L. bagri Dana, 1852; L. bifurcatus Wilson, 1905; L. christianensis Wilson, 1944; L. crabro Krøyer, 1863; L. eminens Wilson, 1944; L. eurus Bere, 1936; L. exculptus Fischer, 1860; L. interitus Wilson, 1921; L. lichiae Barnard, 1948; L. longipes Wilson, 1905; L. marceps Wilson, 1944; L. monacanthus Heller, 1865; L. perpes Leigh-Sharpe, 1934; L. plotosi Barnard, 1948; L. quadratus Krøyer, 1863; and L. unispinosus Pearse, 1952. However, most of them are clearly distinguishable from $L$. simplex by the structure of certain appendages or in certain parts of the body.

While L. appendiculatus, L. bifurcatus and L. eurus differ from $L$. simplex in having their sternal furca equipped with a pair of bifid tines, L. bagri, L. crabro, $L$. eminens and L. lichiae are distinguishable from the new species in possessing a 2-segmented abdomen which is longer than wide. Three species, L. monacanthus, L. quadratus, and L. unispinosus, are characterised in having the exopod of leg 1 tipped with a single, large process, and another three species, $L$. interitus, $L$. longipes, and $L$. perpes can be differentiated from $L$. simplex by the possession of a bifid dentiform process on the maxillule. Both L. exculptus and L. marceps are different from $L$. simplex in the form of the abdomen, which is longer than the genital complex. L. plotosi is distinguished by bearing a pair of long, rod-like fifth legs. No genuine distinguishing characters can be found between Wilson's (1944) L. christianensis and $L$. simplex. However, it is highly likely that L. christianensis is a junior synonym of Bere's (1936) $L$. marginatus, because both species were found on the same host fish (Galeichthys sp.) from the same geographical area (Pass Christian, Mississippi) and the description of L. christianensis given by Wilson (1944) does not differ much from that provided by Bere (1936) for L. marginatus. Since leg 3 was described by Bere (1936: p. 588) as "of the usual type" for L. marginatus, L. christianensis can accordingly be distinguished from the new species by this feature. Thus, it is concluded that among the 107 species of Lepeophtheirus, only $L$. orbicularis resembles $L$. simplex in carrying a slender element on the proximal segment of the exopod of leg 3 .

Lepeophtheirus orbicularis resembles L. simplex in several other aspects not found in many species of Lepeophtheirus. These similarities are (1) simple dentiform process on the maxillule (see Fig. 2B), (2) 2segmented exopod on leg 3 (due to the fusion of distal two segments, see Fig. 4A), (3) 3-segmented exopod of leg 4 with long proximal, outer spine (see Fig. 4B), and (4) short and broad abdomen, only $1 / 4$ of the length of cephalothoracic shield. However, examination of type specimens of $L$. orbicularis revealed that it is still distinguishable from $L$. simplex. The major differences are found in (1) the structure of the sternal furca, (2) the morphology of the terminal spines on the exopod of leg 1 , and (3) the structure of the terminal claw of male antenna. These three points of differences were also well presented by Shiino (1965). In addition to these three points, the new species can be distinguished from many of its congeners, other than $L$. orbicularis, by the possession of a maxillule with simple dentiform process and a 3 -segmented exopod of leg 4 with a long proximal, outer spine.

Acknowledgements. We would like to thank Kunihiko Izawa for making the necessary arrangements for one of us (JSH) to visit and examine the type specimens of Lepeophtheirus orbicularis kept in the Faculty of Aquatic Biological Resources, Mie University in Tsu, Japan. This study was partially supported by a grant J28342B from CONACYT to one of the junior authors (EF-A). The completion of this manuscript was aided by a grant from the Paramitas Foundation to the senior author (JSH). 
BERE R. 1936: Parasitic copepods from Gulf of Mexico fish. Am. Midl. Nat. 17: 577-625.

CAUSEY D. 1960: Parasitic Copepoda from Mexican coastal fishes. Bull. Mar. Sci. 10: 323-337.

HO J.-S., LIN C.-L. 2000: Anuretes grandis sp. n., a caligid copepod (Siphonostomatoida) parasitic on Diagramma pictum (Thunberg) in Taiwan, with discussion of Anuretes Heller, 1865. Folia Parasitol. 47: 227-234.
SHIINO S.M. 1965: Parasitic copepods of the eastern Pacific fishes. 8. Lepeophtheirus. Rep. Fac. Fish. Prefect. Univ. Mie 5: 441-454.

WILSON C.B. 1944: Parasitic copepods in the United States National Museum. Proc. U.S. Natl. Mus. 94 (3177): 529582.

Accepted 14 November 2000 